Correspondence to: Professor B. K. Nicholson

Chemistry Department

University of Waikato

Private Bag 3105

Hamilton

New Zealand.

Fax 006478384219

e-mail: b.nicholson@waikato.ac.nz

\title{
A structural, spectroscopic and theoretical study of the triphenylphosphine chalcogenide complexes of tungsten carbonyl, $\left[\mathrm{W}\left(\mathrm{XPPh}_{3}\right)(\mathrm{CO})_{5}\right], \mathrm{X}=\mathrm{O}$, S, Se.
}

Julian B. Cook, Brian K. Nicholson* and Derek W. Smith.

Department of Chemistry, University of Waikato, Private Bag 3105, Hamilton, New

\section{Zealand.}

\section{Synopsis}

The structures of $\left[\mathrm{W}\left(\mathrm{XPPh}_{3}\right)(\mathrm{CO})_{5}\right], \mathrm{X}=\mathrm{O}, \mathrm{S}, \mathrm{Se}$ are described, and the bonding of the $\mathrm{Ph}_{3} \mathrm{PX}$ ligand to the metal has been analysed by EHMO methods.

\begin{abstract}
The series $\left[\mathrm{W}\left(\mathrm{XPPh}_{3}\right)(\mathrm{CO})_{5}\right], \mathrm{X}=\mathrm{O}, \mathrm{S}$, Se has been structurally determined by $\mathrm{X}$-ray crystallography and fully characterised spectroscopically to provide data for comparing the bonding of the $\mathrm{Ph}_{3} \mathrm{PX}$ ligands to the metal. The $\mathrm{P}-\mathrm{X}-\mathrm{W}$ angles are $134.3^{\circ}, 113.2^{\circ}$ and $109.2^{\circ}$ respectively for $\mathrm{X}=\mathrm{O}, \mathrm{S}$, Se. The bonding has been analysed using EHMO calculations which suggest that lower P-X-W angles depend on the relative importance of $\sigma$-bonding, which in turn depends on the chalcogen in the order $\mathrm{X}=\mathrm{Se}>\mathrm{S}>\mathrm{O}$. The effect is enhanced by lower energies of the metal $\sigma$ and $\pi$ orbital energies.
\end{abstract}

Keywords: Tungsten complexes, triphenyl phosphine chalcogenide complexes, EHMO calculations, X-ray crystallography structures. 


\section{Introduction}

The triphenylphosphine chalcogenides, $\mathrm{Ph}_{3} \mathrm{PX}(\mathrm{X}=\mathrm{O}, \mathrm{S}, \mathrm{Se})$ are all wellknown as ligands [1,2]. However an examination of the Cambridge Crystallographic Database [3] shows an imbalance in the number of structural characterisations. There are only nine examples of metal complexes with $\mathrm{X}=\mathrm{Se}$, sixteen with $\mathrm{X}=\mathrm{S}$ and nearly three hundred with $\mathrm{X}=\mathrm{O}$. Furthermore, most of those for $\mathrm{X}=\mathrm{O}$ involve metals in higher oxidation states, whereas those for $\mathrm{X}=\mathrm{S}$, Se are for metals in low oxidation states, especially $\mathrm{Au}(\mathrm{I})$. This is understandable since $\mathrm{Ph}_{3} \mathrm{PO}$ is a hard Lewis base preferring hard acids, while $\mathrm{Ph}_{3} \mathrm{PS}$ and $\mathrm{Ph}_{3} \mathrm{PSe}$ are soft bases [1].

Another distinctive feature is the different $\mathrm{P}-\mathrm{X}-\mathrm{M}$ angles found. When $\mathrm{X}=\mathrm{O}$, known angles are $125-180^{\circ}$, while for $\mathrm{X}=\mathrm{S}$ the range is $102-117^{\circ}$ and for $\mathrm{X}=\mathrm{Se}$ it is $97-112^{\circ}$. Interpretation of these trends is hindered by the complications arising from the different metal centres involved, with only Burford's congeneric series $\left(\mathrm{Ph}_{3} \mathrm{PX}\right) \mathrm{AlCl}_{3}(\mathrm{X}=\mathrm{O}, \mathrm{S}, \mathrm{Se})$ allowing direct comparison at a single metal site $[4,5]$. Burford studied in detail the trend in relation to this series of aluminium compounds, culminating in a 1992 review in which it was stated "in general, the oxo complexes adopt the widest angles [about the chalcogen]..., while the thio and seleno complexes adopt the most acute angles at [the chalcogen]" [5].

Independently of Burford, Lobana in his comprehensive review on the coordination chemistry of phosphine chalcogenides [1] also noted that M-X-P angles of tertiary phosphine chalcogenides about the oxygen vary from $113^{\circ}$ to $180^{\circ}$, whereas the corresponding angles about sulfur and selenium lie in the range of $96^{\circ}$ to $120^{\circ}$.

The previous comparative series [4] involved a hard acid, $\mathrm{Al}^{3+}$, so we have now determined the structures of a complete series involving a soft metal centre, viz. 
$\left[\mathrm{W}\left(\mathrm{XPPh}_{3}\right)(\mathrm{CO})_{5}\right](\mathrm{X}=\mathrm{O}, \mathrm{S}, \mathrm{Se}, \mathbf{1 a - c})$. Structural parameters and spectroscopic data are discussed and the bonding is analysed

\section{Experimental Section.}

Preparations were carried out under a nitrogen atmosphere using standard Schlenk techniques. Infrared spectra were recorded on a Digilab Biorad FTS-60, and ${ }^{1} \mathrm{H},{ }^{13} \mathrm{C}\left\{{ }^{1} \mathrm{H}\right\}$ and ${ }^{31} \mathrm{P}\left\{{ }^{1} \mathrm{H}\right\}$ NMR spectra on a Bruker AC300 machine.

All three compounds $\left[\mathrm{W}\left(\mathrm{OPPh}_{3}\right)(\mathrm{CO})_{5}\right],\left[\mathrm{W}\left(\mathrm{SPPh}_{3}\right)(\mathrm{CO})_{5}\right]$ and $\left[\mathrm{W}\left(\mathrm{SePPh}_{3}\right)(\mathrm{CO})_{5}\right][6]$ have been reported, and were prepared according to the literature procedures, involving irradiation of $\left[\mathrm{W}(\mathrm{CO})_{6}\right]$ in thf, followed by addition of the ligand. Isolation of the sulfide and selenide was straightforward, but the oxide was noticeably less stable. Spectroscopic data are listed in Tables 1 and 2.

Crystals for structural studies were obtained from benzene/hexane (for the sulfide) and from toluene/heptane for the other compounds. X-ray data were collected on a Siemens SMART CCD diffractometer. The structures were solved and refined routinely on $\mathrm{F}^{2}$ with all non-hydrogen atoms anisotropic, and with hydrogen atoms riding on the corresponding carbon atoms, using the SHELX programs [7]. Crystallographic details are given in Table 3, selected bond parameters in Table 4 and the structures are illustrated in Figure 1 and 2. Crystallographic data for the structural analysis has been deposited with the Cambridge Crystallographic Data Centre, CCDC No. 219366-8 for compounds 1a-c respectively. Copies of this information may be obtained free of charge from: The Director, CCDC, 12 Union Road, Cambridge, CB2 1EZ, UK, Fax, +44(1223)336-033 or email: deposit@ccdc.cam.ac.uk or www:http://www.ccdc.cam.ac.uk

The secular determinants of model systems studied by Extended Huckel Molecular Orbital calculations were calculated using the MAPLE programme [8], 
while other calculations were performed with SPARTAN 5.0 [9] running on a UNIX based IRIX 6.3.1 operating system on a Silicon Graphics computer.

\section{Results and discussion}

\section{Spectroscopy}

The compounds discussed in this paper, $\left[\mathrm{W}\left(\mathrm{XPPh}_{3}\right)(\mathrm{CO})_{5}\right] \mathrm{X}=\mathrm{O}, \mathrm{S}, \mathrm{Se}$, have been reported previously, so were prepared using the literature procedures [6]. No difficulties were encountered, though it was noted that the oxide underwent slow decomposition in solution, in contrast to the other two examples which appeared indefinitely stable. This can be attributed to the unfavourable soft Lewis acid/hard Lewis base combination with the oxide.

The carbonyl region infrared spectra are listed in Table 1. These generally agree with the frequencies reported in the literature [6], but the values presented here were all obtained in the same solvent so are directly comparable. The values for the $\mathrm{S}$ and Se examples are very similar, indicating that the bonding interactions involving the heavier ligands are closely analogous. However, the values for the $\mathrm{Ph}_{3} \mathrm{PO}$ compound are significantly different; the shifts are as would be expected on simple electronegativity grounds for the $A_{1} "$ and $B_{1}$ modes which shift to higher frequency, but the $\mathrm{E}$ and $\mathrm{A}_{1}{ }^{\prime}$ modes are unexpectedly at lower frequency. This points to a difference in the $\sigma / \pi$ bonding interactions for the $\mathrm{O}$ example compared to the $\mathrm{S}$ and Se ones. This has been assessed by calculating Cotton-Kraihanzel force constants, and derived Graham $\Delta \sigma$ and $\Delta \pi$ parameters [10] (Table 1). These are useful for comparing trends within a series but do not allow absolute assignment of bonding strength because of the underlying assumptions. They indicate that the relative order of $\sigma$-donation is $\mathrm{Ph}_{3} \mathrm{P}>>\mathrm{Ph}_{3} \mathrm{PSe}>\mathrm{Ph}_{3} \mathrm{PS}>>\mathrm{Ph}_{3} \mathrm{PO}$. The relative order of $\pi$ acceptance is the same, but since it is unlikely that $\mathrm{Ph}_{3} \mathrm{PX}$ can act as $\pi$-acceptors it is 
more realistic to state it in terms of the order of $\pi$-donor properties being $\mathrm{Ph}_{3} \mathrm{PO}>>$ $\mathrm{Ph}_{3} \mathrm{PS}>\mathrm{Ph}_{3} \mathrm{PSe}$. The IR data therefore suggest that $\mathrm{Ph}_{3} \mathrm{PO}$ differs from the other two members of the series by being a weaker $\sigma$-donor but stronger $\pi$-donor, while the sulfide and selenide are similar to each other as strong $\sigma$-donors but weaker $\pi$-donors towards the tungsten centre. The bent nature of the bond angles in the series $\left[\mathrm{W}\left(\mathrm{XPPh}_{3}\right)(\mathrm{CO})_{5}\right](\mathrm{X}=\mathrm{O}, \mathrm{S}, \mathrm{Se})$, precludes a simple model separating the $\sigma / \pi$ bonding interactions in terms of atomic orbitals so the conclusions are general, merely that for the $X=S$, Se examples the $\sigma$-bonding is relatively more important than the $\pi$ interactions, compared with $\mathrm{X}=\mathrm{O}$.

The infrared spectra of the P-X bonds have been reported before, and show a $19-45 \mathrm{~cm}^{-1}$ decrease in stretching frequency on complex formation [11]. This is consistent with the small increase in P-X bond lengths when the ligands are attached to the $\mathrm{W}(\mathrm{CO})_{5}$ groups, as discussed below. The drop in $\mathrm{v}(\mathrm{P}-\mathrm{X})$ on coordination has been interpreted as a weakening of the $\mathrm{P}-\mathrm{X}$ bond, and there is a moderate correlation of $\Delta v(\mathrm{P}-\mathrm{X})$ with the Lewis acidity of the metal centre to which it is coordinated [11]. However simple quantitative use of $\Delta v(\mathrm{PX})$ in determining the degree of disruption of the $\mathrm{P}-\mathrm{X}$ bond is prevented by several factors: $\Delta v(\mathrm{PX})$ depends on the M-X-P angle because of both kinematic and hybridisation effects [12]; the coupling of the M-X and $\mathrm{X}-\mathrm{P}$ vibrations has the effect of raising $\mathrm{v}(\mathrm{PX})$; the mass of $\mathrm{M}$ and the strength of the M-X bond will affect $v(\mathrm{PX})$. Nevertheless, Burford's interpretation of $\Delta v(\mathrm{PX})$ data [5] that the P-S bond (and by analogy the P-Se bond) undergoes a more dramatic electronic perturbation upon coordination than does the analogous $\mathrm{P}-\mathrm{O}$ bond appears reasonable.

For the NMR data, only the ${ }^{31} \mathrm{P}$ and carbonyl ${ }^{13} \mathrm{C}$ of the oxide have been previously presented. The full data are listed in Table 2 . There are no sensible trends 
in absolute values for the ${ }^{31} \mathrm{P}$ data for the compounds, while the shifts from the values for the corresponding free ligands are 15.1, 4.5 and $-3.6 \mathrm{ppm}$ respectively for the $\mathrm{O}$, $\mathrm{S}$, and Se examples. The interpretation of ${ }^{31} \mathrm{P}$ shifts is notoriously difficult and no explanation for the values found is proffered here. It is noted that the large downfield shift in the ${ }^{31} \mathrm{P}$ resonance upon coordination of $\mathrm{R}_{3} \mathrm{PO}$ ligands to metal centres has been interpreted as disrupting the P-O $\sigma$-bond framework. [4,5]

The ${ }^{13} \mathrm{C}$ data for the phenyl rings are unexceptional, with closely similar small shifts from the free ligand data in each case. These follow the previously reported pattern of an upfield shift in the ${ }^{13} \mathrm{C}$ resonance of the ipso carbon, and a downfield shift in the para carbon of $\mathrm{Ph}_{3} \mathrm{PO}$ on adduct formation, which has been used as evidence of disruption of the $\mathrm{P}-\mathrm{O} \pi$ interaction $[4,5]$. This assumes that a decreased P$\mathrm{O} \pi$ interaction will allow greater $\pi$ interaction between the ipso carbon and the phosphorus (a $\pi$-interaction between the phenyl rings of $\mathrm{Ph}_{3} \mathrm{PX}, \mathrm{X}=\mathrm{O}, \mathrm{S}, \mathrm{Se}$ and the phosphorus atom has been demonstrated [13]).

Interestingly the usual increase in the ${ }^{1} \mathrm{~J}_{\mathrm{PC}}$ to the ipso carbon atom when $\mathrm{Ph}_{3} \mathrm{PO}$ coordinates to Lewis acids [4] is not observed with the $\mathrm{W}(\mathrm{CO})_{5}$ example where there is no significant change.

The carbonyl ${ }^{13} \mathrm{C}$ resonances are also close amongst the series, with those of the oxide slightly but detectably different from the other two, which are barely distinguishable.

\section{Structures}

The three compounds have similar structures, though they each crystallise in a different space group. The overall geometry is illustrated in Figure 1. As expected, the tungsten has approximately octahedral coordination, with five $\mathrm{CO}$ groups and the chalcogen atom occupying the sixth site. The orientation of the P-X vector with 
respect to the equatorial CO ligands varies as shown in Figure 2, but this is presumably because of the different crystal packing trapping a group with a low rotational barrier, so has no significance in terms of the bonding interactions between the ligand and the tungsten atom.

The parameter of most interest in the structures is the W-X-P angles; these are detailed in Table 4 and compared in Table 5 with the corresponding values for the only other complete series, $\left(\mathrm{Ph}_{3} \mathrm{PX}\right) \mathrm{AlCl}_{3}$, and with the range and average values for compounds retrieved from the Cambridge Crystallographic Database [3].

The value for $\left[\mathrm{W}\left(\mathrm{OPPh}_{3}\right)(\mathrm{CO})_{5}\right]$ is $134.3^{\circ}$, one of the lowest reported for the $\mathrm{Ph}_{3} \mathrm{PO}$ ligand, with only $\left[\mathrm{Pd}\left(\mathrm{OPPh}_{3}\right)\left(\mathrm{NO}_{3}\right)_{2}\left(\mathrm{PPh}_{3}\right)\right]\left(132.1^{\circ}\right)[14]$ and a dimeric bismuth example $\left(125.5^{\circ}\right)$ [15] showing a lower value. It is clearly dramatically lower than the $180^{\circ}$ found for $\left(\mathrm{Ph}_{3} \mathrm{PO}\right) \mathrm{AlCl}_{3}\left(180^{\circ}\right)[4]$. However it is significantly wider than the angles in the analogous $\left[\mathrm{W}\left(\mathrm{SPPh}_{3}\right)(\mathrm{CO})_{5}\right]\left(113.2^{\circ}\right)$ and $\left[\mathrm{W}\left(\mathrm{SePPh}_{3}\right)(\mathrm{CO})_{5}\right]$ $\left(109.2^{\circ}\right)$ which are towards the upper end of the narrow range reported for other examples (Table 4), and are slightly higher than the angles in the related $\left(\mathrm{Ph}_{3} \mathrm{PX}\right) \mathrm{AlCl}_{3}$ compounds [4,5]. For comparison, the compounds $\left[\mathrm{Cr}\left(\mathrm{SPMe}_{3}\right)(\mathrm{CO})_{5}\right]$ and $\left[\mathrm{W}\left(\mathrm{SePPh}_{3}\right)(\mathrm{CO})_{3} \mathrm{Cp}\right]\left[\mathrm{ClO}_{4}\right]$ have $\mathrm{M}-\mathrm{X}-\mathrm{P}$ angles of $112.5^{\circ}$ and $111.4^{\circ}$ respectively $[16,17]$.

The $\mathrm{W}-\mathrm{X}$ bond lengths are given in Table 4 . In each case they are towards the longer end of the range observed in other compounds. The W-O bond in $\left[\mathrm{W}\left(\mathrm{OPPh}_{3}\right)(\mathrm{CO})_{5}\right]$ is only slightly longer than those in analogous complexes $\left[\mathrm{W}\left(\mathrm{OPPh}_{2} \mathrm{CHPPh}_{3}\right)(\mathrm{CO})_{5}\right][18]$ and $\left[\mathrm{W}\left(\mathrm{OPPh}_{2} \mathrm{NPPh}_{3}\right)(\mathrm{CO})_{5}\right][19]$, but is $0.3-0.4 \AA$ longer than examples with formal W-O single bonds [3]. The corresponding W-X bonds in $\left[\mathrm{W}\left(\mathrm{SPPh}_{3}\right)(\mathrm{CO})_{5}\right]$ and $\left[\mathrm{W}\left(\mathrm{SePPh}_{3}\right)(\mathrm{CO})_{5}\right]$ are up to $0.2 \AA$ longer than formal W-S or W-Se bonds involving other types of ligands. The increase in W-X lengths 
going from $\mathrm{O} \rightarrow \mathrm{S} \rightarrow \mathrm{Se}$ are $0.357 \AA$ and $0.117 \AA$, which is attenuated compared to the formal increase in covalent radii of the atoms (O $0.66 \AA$, S $1.04 \AA$, Se $1.17 \AA,[20])$, where increases of 0.38 and 0.13 are predicted.

The P-X bonds show an increase over the distances in the uncomplexed ligands, with perturbation of the P-O bond less in both absolute and relative terms than that for the heavier congeners.

All this points to a somewhat weak $\mathrm{W}-\mathrm{X}$ interaction overall, especially for the O example.

There is no significant difference in the average equatorial $\mathrm{W}-\mathrm{CO}$ bond lengths among the three examples, but the axial W-CO bond lengths (which are shorter than the equatorial ones as expected) show a slight increase as the transchacogenide gets heavier suggesting that $\mathrm{O}$ has the lowest trans-influence.

The endo X-W-C angles of the complexes $\left[\mathrm{W}\left(\mathrm{XPPh}_{3}\right)(\mathrm{CO})_{5}\right]$ are all larger than the corresponding exo angles (as defined in 2), the deviation increasing $\mathrm{O} \rightarrow \mathrm{S} \rightarrow \mathrm{Se}$ as shown by the values of $3.9^{\circ}, 4.7^{\circ}$ and $9.4^{\circ}$ for the angle between the $\mathrm{X}-$ $\mathrm{W}$ vector and the normal to the least-squares plane defined by the equatorial carbon atoms. This trend is the opposite expected if it was caused by steric interactions between the phenyl rings and the equatorial carbonyl groups, since these would be less for $\mathrm{Ph}_{3} \mathrm{PSe}$ because of the longer W-Se and Se-P bonds. Burfood [5] noted a corresponding effect for $\left(\mathrm{Ph}_{3} \mathrm{PX}\right) \mathrm{AlCl}_{3}(\mathrm{X}=\mathrm{S}, \mathrm{Se})$ and concluded that the $\mathrm{P}-\mathrm{X}$ bond was coordinated in a "side-on" mode and that the bonding could be described as a partial $\eta^{2}$-type (implying an interaction between the phosphorus and aluminium atoms).

There are no statistically significant changes in the $\mathrm{P}-\mathrm{C}_{\text {aryl }}$ nor C-P-C angles between the coordinated and free $\mathrm{Ph}_{3} \mathrm{PX}$ ligands. 
The series of $\left[\mathrm{W}\left(\mathrm{XPPh}_{3}\right)(\mathrm{CO})_{5}\right]$ structures allows the following conclusions:

(i) the bonding between $\mathrm{W}$ and $\mathrm{X}$ is relatively weak for all three members, comparatively more so for $\mathrm{X}=\mathrm{O}$;

(ii) the trend of decreasing $\mathrm{W}-\mathrm{X}-\mathrm{P}$ bond angles as $\mathrm{X}$ gets heavier is marked, but not as dramatic as in the $\mathrm{AlX}_{3}$ series;

(iii) the degree of disruption of the $\mathrm{X}-\mathrm{P}$ bond increases as $\mathrm{X}=\mathrm{O}<\mathrm{S}<\mathrm{Se}$ upon complex formation.

\section{Theoretical analysis.}

The free ligands $P h_{3} P X$.

Before investigating the complexation of $\mathrm{Ph}_{3} \mathrm{PX}$ to metal centres, the electronic structure of the free ligand needs to be addressed. There has been extensive theoretical study of $\mathrm{Ph}_{3} \mathrm{PO}$, as reviewed by Gilheany [21, 22], though much less attention has been devoted to the heavier congeners. A general model for the P-O bond is one where there is $\sigma$-donation of the lone pair on the $\mathrm{R}_{3} \mathrm{P}$ moiety to the empty $\mathrm{p}_{\mathrm{z}}$ orbital of the oxygen atom, with back donation from the filled $\mathrm{O} \mathrm{p}_{\mathrm{x}^{-}}$and $\mathrm{p}_{\mathrm{y}}$-orbitals to the $\pi$-acceptor orbitals on the phosphine. The contentious issue is the form of the $\pi$ acceptor orbitals, with early attribution to empty $\mathrm{d} \pi$-type orbitals being superseded by the P-C $\sigma^{*}$ orbitals. The heavier examples $\mathrm{Ph}_{3} \mathrm{PX}(\mathrm{X}=\mathrm{S}, \mathrm{Se})$ have been less-well studied, but are expected to conform to a similar picture.

We have performed $a b$ initio Hartree-Fock calculations on the free ligands $\mathrm{Ph}_{3} \mathrm{PX}(\mathrm{X}=\mathrm{O}, \mathrm{S}, \mathrm{Se})$ to gain quantitative bond order and atomic valence data so that the electronic structures can be compared. Single point (i.e. fixed geometry) calculations used P-X, P-C, C-P-C and C-P-X bond parameters from the reported crystal structures, C-C-P-X torsion angles of -140 degrees and $\mathrm{C}_{3}$ symmetry. The basis sets used were STO-3G, 3-21G* and 6-31G*. The detailed results depend on 
the basis set but the trends are similar in each case. The measures of bond order and atomic valency are valuable for comparisons amongst the three ligands.

The results are listed in Table 6. The calculated P-X bond orders confirm both the multiple nature of the P-X bond and that the bond order decreases as $\mathrm{X}=\mathrm{O}>\mathrm{S}>$ Se. This is in agreement with previous theoretical studies on the $\mathrm{P}-\mathrm{O}$ bond in $\mathrm{R}_{3} \mathrm{PO}$ [22-24] which showed, in agreement with experimental data, that the P-O bond has multiple character and is highly polarised. The data show the P-S and P-Se bond orders are markedly less than that of the P-O bond at all levels of calculation. A similar trend is apparent with the atomic valency results where both the phosphorus and chalcogen valencies decrease as $\mathrm{X}=\mathrm{O}>\mathrm{S}>\mathrm{Se}$ (Table $6 \mathrm{~b}$ ).

These results are completely consistent with earlier findings for $\mathrm{Ph}_{3} \mathrm{PX}$, summarised below:

(i) the P-X bonding interaction may be understood as forward donation of the phosphorus lone pair to a vacant orbital on the chalcogen, followed by backdonation of $\pi$-electron density from filled p-orbitals on the chalcogen to appropriate $\pi$-acceptors on the phosphorus;

(ii) the P-O bond is strong, short and polar; the thio- and seleno- analogues exhibit the same characteristics, although to a lesser degree;

(iii) the multiple bond characteristic of the P-X bond of tertiary phosphine chalcogenides decreases as $\mathrm{X}=\mathrm{O}<\mathrm{S}<\mathrm{Se}$;

(iv) both the $\sigma$ - and $\pi$-bond strength of the $\mathrm{P}$-X bond increases as $\mathrm{X}=\mathrm{Se}<\mathrm{S}<\mathrm{O}$;

(v) the geometry of the $\mathrm{PPh}_{3}$ unit of a $\mathrm{Ph}_{3} \mathrm{PX}$ ligand is predicted to be affected by changes in the nature of the X-P interaction brought about by coordination of the chalcogen to a Lewis acid.

The bonding of $\mathrm{Ph}_{3} \mathrm{PX}$ to metal atoms. 
EHMO analysis

Extended Hückel MO (EHMO) calculations were performed to determine the changes in bonding as the W-X-P angle $\theta$ is varied. It is difficult to extract meaningful information from the multitude of filled MOs arising from a full calculation for $\left[\mathrm{W}\left(\mathrm{XPPh}_{3}\right)(\mathrm{CO})_{5}\right]$. Accordingly a simplified three-body W-X-P model was adopted, as shown in Figure 3.

The $\mathrm{W}(\mathrm{CO})_{5}$ fragment contributes one $\sigma$ orbital directed along the $\mathrm{y}$-axis $-\mathrm{a}$ hybrid of tungsten $5 \mathrm{~d}, 6 \mathrm{~s}$ and $6 \mathrm{p}$ orbitals whose composition cannot be specified - and an in-plane (xy) $\pi$ orbital, primarily tungsten $5 \mathrm{~d}$ in composition. Likewise the $\mathrm{PR}_{3}$ group has a $\sigma$ orbital (principally a hybrid of phosphorus $3 \mathrm{~s}$ and $3 \mathrm{p}$ ) pointing towards the $\mathrm{X}$ atom and an in-plane $\pi$ orbital whose composition need not be specified. The chalcogen atom contributes its $n s, n p_{x}$ and $n p_{y}$ orbitals. Out-of-plane $\pi$ bonding need not be considered since, to a good approximation, it will be unaffected by variation of the angle $\theta$. In the EHMO scheme [25] the energies of the MOs are eigenvalues $E$ of the determinantal equation:

$$
\left|H_{\mathrm{ij}}-E S_{\mathrm{ij}}\right|=0
$$

The diagonal terms $H_{\mathrm{ii}}$ for the chalcogen atomic orbitals were equated to the negatives of the valence orbital ionisation potentials (VOIPs) which can be obtained from atomic spectra [26] in the usual way [27], and are listed in Table 7. 
$H_{\mathrm{ii}}$ for the $\sigma$ orbital on the $\mathrm{W}(\mathrm{CO})_{5}$ fragment was varied between -2 and $-9 \mathrm{eV}$, to cover the range in composition between $\mathrm{W}(6 \mathrm{p})$ and $\mathrm{W}(5 \mathrm{~d}) ; H_{\mathrm{ii}}$ for the $\mathrm{W}(\mathrm{CO})_{5} \pi$ orbital was set $3 \mathrm{eV}$ lower than the value for the $\sigma$ orbital. For the $\mathrm{PR}_{3}$ group, the $H_{\mathrm{ii}}$ were taken to be $-9 \mathrm{eV}(\sigma)$ and $-3 \mathrm{eV}(\pi)$. The off-diagonal terms $H_{\mathrm{ij}}$ are given by the Wolfsberg-Helmholz approximation:

$$
H_{\mathrm{ij}}=1 / 2 K S_{\mathrm{ij}}\left(H_{\mathrm{ii}}+H_{\mathrm{jj}}\right)
$$

where $K$ takes the value 1.75 as recommended by Hoffmann [25] and $S_{\mathrm{ij}}$ is the overlap integral. The overlap integrals cannot be calculated explicitly since the compositions of the hybrids based on the $\mathrm{W}(\mathrm{CO})_{5}$ and $\mathrm{PR}_{3}$ groups are unknown; estimates had to be made.

The chalcogen $n p_{x}$ and $n p_{y}$ orbitals can engage in both $\sigma$ and $\pi$ overlap. Two sets of calculations were performed:

(i) considering only $\sigma$ bonding

(ii) considering $\sigma$ and $\pi$ bonding, with emphasis on the role of $\sigma-\pi$ mixing in determining the optimum W-X-P angle.

\section{бBonding Only Model}

A five orbital model was used, incorporating the chalcogen $n s, n p_{x}$ and $n p_{y}$ orbitals together with $\sigma$ hybrids on the $\mathrm{P}$ and $\mathrm{W}$ atoms. The phosphine group contributes two electrons and the chalcogen atom $\mathrm{X}$ four, the remaining two $\mathrm{X}$ electrons being 
assigned to the nonbonding $\mathrm{np}_{\mathrm{z}}$ orbital; the $\sigma$ hybrid based on the $\mathrm{W}$ atom is empty.

These lead to two bonding and two antibonding MOs, plus a nonbonding MO which can be approximated as a lone pair on $\mathrm{X}$ (the other lone pair being the $\mathrm{np}_{\mathrm{Z}}$ orbital). As already noted, the overlap integrals $S_{\mathrm{ij}}$ in eqn. (1) cannot be calculated explicitly since the hybrid orbitals $\mathrm{W} \sigma$ and $\mathrm{P} \sigma$ on the $\mathrm{W}(\mathrm{CO})_{5}$ and $\mathrm{PR}_{3}$ groups respectively are of unspecified composition. Guided by tabulated values of two-centre overlap integrals $[28,29]$ and intuition, the following values were adopted:

$S(\mathrm{~W} \sigma, \mathrm{ns})=0.20$

$S(\mathrm{~W} \sigma, \mathrm{np})=0.25$

$S(\mathrm{P} \sigma, \mathrm{ns})=0.25$

$S(\mathrm{P} \sigma, \mathrm{np})=0.30$

Thus the angular dependence of the MOs obtained by solution of eqn. (1) lies in the overlap integrals $S\left(\mathrm{P} \sigma, n p_{\mathrm{x}}\right)$ and $S\left(\mathrm{P} \sigma, \mathrm{np} \mathrm{y}_{\mathrm{y}}\right)$ which are equal to $(0.30 \sin \theta)$ and $(0.30 \cos \theta)$ respectively.

The W-X-P angle of lowest energy was $90^{\circ}$ (corresponding to $\theta=0^{0}$, as defined in Figure 3) in all calculations performed. An orbital interaction diagram representing the system when the M-X-P angle is $180^{\circ}$ appears as Figure 4 . The forms of the orbitals are: $\psi_{3}$ is a non-bonding pure $\mathrm{np}_{\mathrm{x}}$-orbital; $\psi_{2}$ is a fully bonding combination of the chalcogen $\mathrm{np}_{\mathrm{y}}$-orbital, $\mathrm{P} \sigma$ and $\mathrm{M} \sigma$ orbitals; $\psi_{1}$ is predominantly the ns-orbital of the chalcogen.

Tracking the energies of the individual orbitals showed that $\psi_{3}$ fell while $\psi_{2}$ rose in energy monotonically over the range $180^{\circ}$ to $90^{\circ}$. As the M-X-P angle drops from $180^{\circ}$ the chalcogen $\mathrm{np}_{\mathrm{x}}$-orbital is no longer orthogonal to the remaining orbitals 
and thus $\psi_{3}$ falls in energy as the bonding interaction to P $\sigma$ increases. In contrast $\psi_{2}$ rises in energy as the bonding interaction to P $\sigma$ reduces. The fall in energy of $\psi_{3}$ is greater than the rise in energy of $\psi_{2}$ and so the favoured angle is $90^{\circ}$. The driving force for a $90^{\circ} \mathrm{M}-\mathrm{X}-\mathrm{P}$ angle is the need for both the p-orbitals on the chalcogen to be involved in bonding.

The most important result to emerge from this set of calculations is the relative strength of $\sigma$-bonding for the oxide, sulfide and selenide. The strength of $\sigma$-bonding was assessed by the difference in the total energy of the system at $180^{\circ}$ and $90^{\circ}$. This difference reflects the additional stabilisation in energy gained by the formation of two $\sigma$-bonds with two independent chalcogen p-orbitals compared to the formation of two $\sigma$-bonds with one chalcogen p-orbital. This provides a relative measure of the strength of $\sigma$-bonding. Figure 5 plots the difference in energy between $180^{\circ}$ and $90^{\circ}$ as a function of the energy of the M $\sigma$ orbital. A positive energy difference indicates that the energy at $90^{\circ}$ is lower than at $180^{\circ}$. It is apparent that as the $\sigma$-orbital on the metal drops in energy the relative preference for a M-X-P angle of $90^{\circ}$ increases. This is rationalised by an increased overlap of the $\mathrm{M} \sigma$ orbital to the chalcogen p-orbitals. At any one point (except when $\mathrm{E}(\mathrm{M} \sigma)=-2 \mathrm{eV}$ ), the relative magnitudes of the energy differences increase as $\mathrm{X}=\mathrm{O}<\mathrm{S}<\mathrm{Se}$. This indicates that within the approximations of EHMO theory and the model system used the tendency for the W-X-P angle to approach $90^{\circ}$ increases in the order $\mathrm{X}=\mathrm{O}<\mathrm{S}<$ Se.

\section{Sigma And Pi Bonding Model}

The same three-body model defined in Figure 3 was adopted with the addition of $\pi$-type hybrids on the metal and phosphorus fragments. The aim of this model was to investigate the importance of $\sigma-\pi$-mixing. 
The metal $\pi$-type orbital is modelled after the $\pi$-donor of $\mathrm{W}(\mathrm{CO})_{5}$ and is a filled $d_{x y}$ orbital. The electron count follows the $\sigma$-bonding only model with the addition of two electrons from the $\pi$-donor of $\mathrm{W}(\mathrm{CO})_{5}$ which brings the total electron count to eight. The model creates three bonding, three antibonding and one nonbonding orbital. The $\pi$-type hybrid on the phosphorus is unspecified in nature. Overlap integrals were the same as the $\sigma$-bonding only model with the addition of two new integrals for the $\pi$-type overlaps:

$\mathrm{S}(\mathrm{M} \pi, \mathrm{Xp})=0.075$

$\mathrm{S}(\mathrm{P} \pi, \mathrm{Xp})=0.075$

The angular dependence in the secular determinant lay in: $\mathrm{S}\left(\mathrm{np}_{\mathrm{y}}, \mathrm{P} \sigma\right)=(0.30 \sin \theta)$; $\mathrm{S}\left(n p_{y}, \mathrm{P} \pi\right)=(0.075 \cos \theta) ; \mathrm{S}\left(n p_{x}, \mathrm{P} \sigma\right)=(0.30 \cos \theta) ; \mathrm{S}\left(n p_{x}, \mathrm{P} \pi\right)=(0.075 \sin \theta)$

Table 8 presents the angles of minimum total electronic energy for $\mathrm{X}=\mathrm{O}, \mathrm{S}, \mathrm{Se}$, located to within $1^{\circ}$ accuracy. When the energy of the metal $\sigma$ - and $\pi$-orbitals was less than -5 and $-8 \mathrm{eV}$, respectively, the preferred angle was $90^{\circ}$. The results show a clear trend in the bond angles, that is the M-X-P angle decreases according to the chalcogen as $\mathrm{X}=\mathrm{O}>\mathrm{S}>\mathrm{Se}$.

It is proposed that the drop in the angle of minimum energy as the energies of the tungsten orbitals drop is due to the increasing importance of $\sigma$-bonding which favours lower angles. More generally the results are indicative that electronic influences localised to the M-X-P unit (and ultimately the electronic nature of the chalcogen) are responsible for the observed bond angles and the trends in M-X-P angles of phosphine chalcogenide adducts. These calculations discount the possibility that the observed 
trends in bond angles are wholly due to steric factors (the larger the chalcogen then the more acute the angle may be as the two groups on each side are more separated), and hence the inverse relationship of bond angles and atomic radii of the chalcogens.

The results of the EHMO calculations allow two important conclusions to be reached which would have otherwise been obscured by higher level calculations:

(1) $\sigma$-bonding increases in importance according to the chalcogen as $\mathrm{X}=\mathrm{O}<\mathrm{S}<$ Se.

(2) the bond angle trends are due to electronic influences inside the M-X-P unit and are not steric in nature.

The correlation of increasing $\sigma$-bond strength and decreasing M-X-P angle should also be noted. The increase in the relative importance of $\sigma$-bonding according to the chalcogen as $\mathrm{X}=\mathrm{O}<\mathrm{S}<\mathrm{Se}$ is partially responsible for the observed bond angles.

\section{Acknowledgement.}

We thank Associate Professor C. Rickard and Dr A. Oliver, University of Auckland, for collection of X-ray intensity data. 


\section{References}

1. T. S. Lobana in F. R. Hartley (Ed) The Chemistry of Organophosphorus Compounds, Vol 2, Ch 8, Wiley, 1992.

2. S. E. Livingstone, in G. Wilkinson, R. D. Gillard and J. A. McCleverty (Eds) Comprehensive Coordination Chemistry, Pergamon, 1987, Vol 2, Ch 16.

3. Cambridge Crystallographic Data Base, April 2003 version, c.f. F. H. Allen, Acta Cryst, 2002, B58, 380.

4. N. Burford, B. W. Royan, R. E. H. Spence, T. S. Cameron, A.Linden and R. D. Rogers, J. Chem. Soc., Dalton Trans., 1990, 1521; N. Burford, B. W. Royan, R. E. H. Spence and R. D. Rogers, J. Chem. Soc., Dalton Trans., 1990, 2111.

5. N. Burford, Coord. Chem. Rev., 1992, 112, 1.

6. P. M. Boorman, S. A. Clow, D. Potts and H. Wieser, Inorg. Nucl. Chem. Lett., 1973, 9, 941; E. W. Ainscough, A. M. Brodie and A. R. Furness, J. Chem. Soc., Dalton Trans., 1973, 2360; D. J. Daresbourg, M. Pala, D. Simmons and A. L. Rheingold, Inorg. Chem., 1986, 25, 3537.

7. G. M. Sheldrick, SHELX-97--Programs for X-ray Crystal Structure Determination, University of Gottingen, 1997.

8. B. W. Char, K. O. Geddes, G. H. Gonnet, B. L. Leong, M. B. Monagan and S. M. Watt, MAPLE V Library Reference Manual, Springer-Verlag, New York, 1991.

9. Spartan 5.0, Wavefunction Inc., 18401 Von Karman Ave., Ste 370, Irvine CA92612, USA.

10. F. A. Cotton and C. S. Kraihanzel, J. Amer. Chem. Soc., 1962, 84, 4432; W. A. G. Graham, Inorg. Chem., 1968, 7, 315 . 
11. R. A. Jorge, C. Airoldi and A. P. Chagas, J. Chem. Soc., Dalton Trans., 1978, 1102; F. A. Cotton, R. D. Barnes and E. Bannister, J. Chem. Soc., 1960, 2199;

J. Sheldon and S. Y. Tyree, J. Amer. Chem. Soc., 1958, 80, 4775; M. J.

Frazer, W. Gerrard and R. Twaits, J. Inorg. Nucl. Chem., 1963, 25, 637; M.

G. King and G. P. McQuillan, J. Chem. Soc., (A), 1967, 898.

12. S. Milicev and D. Hadzi, Inorg. Chim. Acta, 1977, 21, 201.

13. T. A. Albright, W. J. Freeman and E. E. Schweizer, J. Org. Chem., 1975, 40,

3437; B. J. Dunne and A. G. Orpen, Acta Cryst., 1991, C47, 345.

14. C. J. Jones, J. A. McCleverty, A. S. Rothin, H. Adams and N. A. Bailey, J. Chem. Soc., Dalton Trans., 1986,2055.

15. C. J. Carmalt, A. H. Cowley, A. Decken and N. C. Norman, J. Organometal. Chem., 1955, 496, 59.

16. E. N. Baker and B. R. Reay, J. Chem. Soc., Dalton Trans., 1973, 2205.

17. J. C. Thorne and P. G. Jones, Acta Cryst., 1996, 52, 1084.

18. S. G. Goldberg and K. N. Raymond, Inorg. Chem., 1973, 12, 2923

19. D. J. Darensbourg, M. Pala, D. Simmons, and A. L. Rheingold, Inorg. Chem., $1986,25,3537$.

20. K. M. Mackay, R. A. Mackay and W. Henderson, Introduction to Modern Inorganic Chemistry, $6^{\text {th }}$ Ed, Nelson Thornes, Cheltenham, 2002, p49.

21. D. G. Gilheaney, in F. R. Hartley (Ed), The Chemistry of Organophosphorus Compounds, Wiley, Chichester, 1993, Vol 3, p 1.

22 D. G. Gilheaney, Chem. Rev., 1994, 94, 1339.

23. R. P. Messmer, J. Amer. Chem. Soc., 1991, 113, 433.

24. A. E. Reed, P. V. R. Schleyer, J. Amer. Chem. Soc., 1990, 112, 1434; I. Absar and J. R. Van Wazer, J. Amer. Chem. Soc., 1972, 94, 2382, 6284; H. 
Marsmann, L. C. D. Groenweghe, L. J. Schoad and J. R. Van Wazer, J. Amer. Chem. Soc., 1970, 92, 6108; H. Wallmeier and W. Kutzelnigg, J. Amer. Chem. Soc., 1979, 101, 2804; A. Streitwieser, A. Rajca, R. S. McDowell and R. Glaser, J. Amer. Chem. Soc., 1987, 109, 4184; M. W. Schmidt and M. S. Gordon, J. Amer. Chem. Soc., 1985, 107, 1922; M. W. Schmidt, S. Yabushita and M. S. Gordon, J. Phys. Chem., 1984, 88, 382; P. Molina, M. Majarin, C. L. Leonardo, R. M. Claramunt, M. C. Foces-Foces, F. H. Cano, J. Catalan, J. L. G. de Poz, J.Elgnero, J. Amer. Chem. Soc., 1989, 111, 355; I. H. Hiller and V. R. Saunders, J. Chem. Soc., (A) 1970, 2475; I. H. Hiller and V. R. Saunders, J. Chem. Soc., (A) 1971, 664; I. H. Hiller and V. R. Saunders, J. Chem. Soc., Dalton Trans., 1972, 21; M. F. Guest, I. H. Hiller and V. R. Saunders, J. Chem. Soc., Faraday Trans. 2, 1972, 867; D. L. Bryce, K. Eichele and R. E. Wasylishen, Inorg. Chem., 42 (2003) 5085.

25. R. Hoffmann, J. Chem. Phys., 1963, 39, 1397.

26 C.E. Moore, Atomic Energy Levels, U.S. National Bureau of Standards, Washington DC, 1971.

27 S.P. McGlynn, L.G. Vanquickenborne, M. Kinoshita and D.G. Carroll, Introduction to Applied Quantum Chemistry, Holt-Rinehart-Winston, New York, 1972, pp. 103-112.

28 R. S. Mulliken, C. A. Riecke, D. Orloff and H. Orloff, J. Chem. Phys., 1949, 17, 1248.

29 H. H. Jaffé and G. O. Doak, J. Chem. Phys., 1953, 21, 196. 
Table 1. Infrared data and derived parameters for $\left[\mathrm{W}\left(\mathrm{XPPh}_{3}\right)(\mathrm{CO})_{5}\right]$

$\underline{\left.\text { Infrared data (cyclohexane, } \mathrm{cm}^{-1}\right):}$

$\begin{array}{lcccc} & \mathrm{A}^{\prime \prime}(\mathrm{m}) & \mathrm{B}_{1}(\mathrm{~m}) & \mathrm{E}(\mathrm{vs}) & \mathrm{A}_{1}^{\prime}(\mathrm{s}) \\ {\left[\mathrm{W}\left(\mathrm{OPPh}_{3}\right)(\mathrm{CO})_{5}\right]} & 2069 & 1981 & 1923 & 1890 \\ {\left[\mathrm{~W}\left(\mathrm{SPPh}_{3}\right)(\mathrm{CO})_{5}\right]} & 2069 & 1973 & 1932 & 1904 \\ {\left[\mathrm{~W}\left(\mathrm{SePPh}_{3}\right)(\mathrm{CO})_{5}\right]} & 2066 & 1971 & 1931 & 1905\end{array}$

Cotton-Kraihanzel force constants $^{\mathrm{a}}$ and Graham parameters ${ }^{\mathrm{b}}$

$\begin{array}{cccccc} & \mathrm{k}_{1} & \mathrm{k}_{2} & \mathrm{k}_{1} & \Delta \sigma & \Delta \pi \\ {\left[\mathrm{W}\left(\mathrm{OPPh}_{3}\right)(\mathrm{CO})_{5}\right]} & 14.68 & 15.85 & 0.46 & +0.90 & -0.90 \\ {\left[\mathrm{~W}\left(\mathrm{SPPh}_{3}\right)(\mathrm{CO})_{5}\right]} & 14.82 & 15.72 & 0.32 & +0.50 & -0.63 \\ {\left[\mathrm{~W}\left(\mathrm{SePPh}_{3}\right)(\mathrm{CO})_{5}\right]} & 14.83 & 15.69 & 0.32 & +0.43 & -0.59\end{array}$

${ }^{\mathrm{a}} \mathrm{k}_{1}$ is the force constant for the axial CO, $\mathrm{k}_{2}$ for the equatorial COs and $\mathrm{k}_{\mathrm{i}}$ is the interaction constant; ${ }^{\mathrm{b}}$ values relative to those for $\mathrm{Ph}_{3} \mathrm{P}$, -ve values refer to relatively greater transfer of electron density from the ligand to the metal. 
Table 2. . ${ }^{31} \mathrm{P}$ and ${ }^{13} \mathrm{C} \mathrm{NMR}$ data for $\left[\mathrm{W}\left(\mathrm{XPPh}_{3}\right)(\mathrm{CO})_{5}\right]$

$\underline{{ }^{31} \mathrm{P} \text { NMR data }\left(\delta, \mathrm{CDCl}_{3}\right)}$

\begin{tabular}{|c|c|c|c|c|c|c|}
\hline & Complex & \multicolumn{3}{|c|}{ Free ligand } & \multicolumn{2}{|l|}{ Difference } \\
\hline$\left[\mathrm{W}\left(\mathrm{OPPh}_{3}\right)(\mathrm{CO})_{5}\right]$ & 44.5 & \multicolumn{3}{|c|}{29.6} & \multicolumn{2}{|l|}{14.9} \\
\hline$\left[\mathrm{W}\left(\mathrm{SPPh}_{3}\right)(\mathrm{CO})_{5}\right]$ & 48.6 & \multicolumn{3}{|c|}{44.1} & \multicolumn{2}{|l|}{4.5} \\
\hline$\left[\mathrm{W}\left(\mathrm{SePPh}_{3}\right)(\mathrm{CO})_{5}\right]^{a}$ & 32.5 & \multicolumn{3}{|c|}{36.1} & \multicolumn{2}{|l|}{-3.6} \\
\hline \multicolumn{7}{|c|}{${ }^{2} \mathrm{~J}_{\mathrm{SeP}} 653 \mathrm{~Hz}$ in the complex, c.f. $730 \mathrm{~Hz}$ in $\mathrm{Ph}_{3} \mathrm{PSe}$. } \\
\hline \multicolumn{7}{|c|}{${ }^{13} \mathrm{C} \mathrm{NMR}$ data $\left(\delta, \mathrm{CDCl}_{3}\right)$} \\
\hline & $\mathrm{C} 1^{\mathrm{a}}$ & $\mathrm{C} 2$ & $\mathrm{C} 3$ & $\mathrm{C} 4$ & $C O(\mathrm{equ})$ & $C O(a x)$ \\
\hline$\left[\mathrm{W}\left(\mathrm{OPPh}_{3}\right)(\mathrm{CO})_{5}\right]$ & $127.9(101)$ & 132.5 & 129.1 & 133.5 & 199.0 & 201.5 \\
\hline $\mathrm{Ph}_{3} \mathrm{PO}$ & $132.6(103)$ & 132.1 & 128.5 & 131.9 & & \\
\hline$\left[\mathrm{W}\left(\mathrm{SPPh}_{3}\right)(\mathrm{CO})_{5}\right]$ & $128.2(85)$ & 133.0 & 129.2 & 133.0 & 197.7 & 199.9 \\
\hline $\mathrm{Ph}_{3} \mathrm{PS}$ & $133.0(85)$ & 132.2 & 128.6 & 131.6 & & \\
\hline$\left[\mathrm{W}\left(\mathrm{SePPh}_{3}\right)(\mathrm{CO})_{5}\right]$ & $127.3(76)$ & 133.2 & 129.2 & 133.0 & 197.7 & 200.2 \\
\hline $\mathrm{Ph}_{3} \mathrm{PSe}$ & $131.9(77)$ & 132.7 & 128.6 & 131.6 & & \\
\hline
\end{tabular}


Table 3.

Crystal and refinement data for the structures $\left[\mathrm{W}\left(\mathrm{XPPh}_{3}\right)(\mathrm{CO})_{5}\right], \mathrm{X}=\mathrm{O}, \mathrm{S}$, Se.

$$
\begin{array}{lll}
{\left[\mathrm{W}\left(\mathrm{OPPh}_{3}\right)(\mathrm{CO})_{5}\right]} & {\left[\mathrm{W}\left(\mathrm{SPPh}_{3}\right)(\mathrm{CO})_{5}\right] \quad\left[\mathrm{W}\left(\mathrm{SePPh}_{3}\right)(\mathrm{CO})_{5}\right]} \\
0.5 \mathrm{C}_{6} \mathrm{H}_{6} & {\left[\begin{array}{ll}
(1 \mathrm{a}) \\
\end{array}\right.}
\end{array}
$$

(1b)

\begin{tabular}{|c|c|c|c|}
\hline Formula & $\mathrm{C}_{23} \mathrm{H}_{15} \mathrm{O}_{6} \mathrm{PW}$ & $\mathrm{C}_{26} \mathrm{H}_{18} \mathrm{O}_{5} \mathrm{PSW}$ & $\mathrm{C}_{23} \mathrm{H}_{15} \mathrm{O}_{5} \mathrm{PSeW}$ \\
\hline$M_{r}$ & 602.17 & 657.27 & 665.13 \\
\hline Colour, habit & yellow needle & yellow prism & yellow fragment \\
\hline Size $/ \mathrm{mm}$ & $1.25 \times 0.15 \times 0.05$ & $0.21 \times 0.20 \times 0.16$ & $0.46 \times 0.43 \times 0.36$ \\
\hline Lattice & orthorhombic & triclinic & monoclinic \\
\hline Space group & Pbca & P-1 & $\mathrm{P} 2{ }_{1} / \mathrm{c}$ \\
\hline $\mathrm{a} / \AA$ & $10.6759(2)$ & $10.1738(1)$ & $13.8962(2)$ \\
\hline $\mathrm{b} / \AA$ & $19.1008(2)$ & $10.5880(2)$ & $9.7388(2)$ \\
\hline $\mathrm{c} / \AA$ & $22.5709(4)$ & $12.9028(2)$ & $16.8688(3)$ \\
\hline$\alpha /^{\circ}$ & 90 & $101.988(1)$ & 90 \\
\hline$\beta /{ }^{\circ}$ & 90 & $99.429(1)$ & $93.569(1)$ \\
\hline$\gamma /{ }^{\circ}$ & 90 & $106.626(1)$ & 90 \\
\hline $\mathrm{U} / \AA^{3}$ & $4602.6(1)$ & $1265.14(2)$ & $2278.47(7)$ \\
\hline $\mathrm{Z}$ & 8 & 2 & 4 \\
\hline $\mathrm{T} / \mathrm{K}$ & 203 & 203 & 203 \\
\hline $\mathrm{T}_{\max , \min }$ & $0.541,0.068$ & $0.608,0.545$ & $0.211,0.142$ \\
\hline$\theta$ range $/^{\circ}$ & $2-28$ & $2-28$ & $2-28$ \\
\hline Total data & 26000 & 9588 & 13789 \\
\hline Unique data $\left(\mathrm{R}_{\text {int }}\right)$ & $5250(0.050)$ & $5600(0.018)$ & $5313(0.0238)$ \\
\hline Observed $(>2 \sigma(\mathrm{I}))$ & 3906 & 5184 & 4639 \\
\hline $\mathrm{R}_{1}(\mathrm{Fo}>4 \sigma(\mathrm{Fo}))$ & 0.0340 & 0.0207 & 0.0257 \\
\hline $\mathrm{wR}_{2}$ & 0.0798 & 0.0534 & 0.0714 \\
\hline GoF & 1.031 & 1.023 & 1.064 \\
\hline Final $\Delta \mathrm{e} / \mathrm{e} \AA^{-3}$ & $1.58 /-1.02$ & $0.59 /-0.68$ & $0.46 /-1.22$ \\
\hline
\end{tabular}

(1c) 
Table 4

Selected bond lengths $(\AA)$ and angles (degrees) for $\left[\mathrm{W}\left(\mathrm{XPPh}_{3}\right)(\mathrm{CO})_{5}\right], \mathrm{X}=\mathrm{O}, \mathrm{S}, \mathrm{Se}$.

$$
\left[\mathrm{W}\left(\mathrm{OPPh}_{3}\right)(\mathrm{CO})_{5}\right] \quad\left[\mathrm{W}\left(\mathrm{SPPh}_{3}\right)(\mathrm{CO})_{5}\right] \quad\left[\mathrm{W}\left(\mathrm{SePPh}_{3}\right)(\mathrm{CO})_{5}\right]
$$
(1a)
(1b)
(1c)

$\begin{array}{llll}\mathrm{W}(1)-\mathrm{X} & 2.244(3) & 2.6009(7) & 2.7175(4) \\ \mathrm{P}(1)-\mathrm{X} & 1.509(3) & 2.004(1) & 2.168(1) \\ \mathrm{W}(1)-\mathrm{C}(1) & 1.942(5) & 1.945(4) & 1.978(5) \\ \mathrm{W}(1)-\mathrm{C}_{\text {equ }} \text { (ave.) } & 2.048 & 2.047 & 2.050 \\ \mathrm{~W}(1)-\mathrm{X}-\mathrm{P}(1) & 134.3(2) & 113.24(4) & 109.18(3) \\ \mathrm{X}-\mathrm{W}(1)-\mathrm{C}(1) & 175.6(2) & 176.8(2) & 171.5(1) \\ \mathrm{X}-\mathrm{W}(1)-\mathrm{C}_{\text {equ }} \text { (ave.) } & 91.3 & 90.7 & 91.1 \\ \mathrm{X}-\mathrm{P}-\mathrm{C}(\text { ave. }) & 110.3 & 111.1 & 111.8\end{array}$


Table 5. Summary of P-X-M angles

Examples in $\mathrm{CCDC}^{\mathrm{a}}$

$\begin{array}{lccccc} & \text { Number } & \text { Range } & \text { Average } & \left(\mathrm{Ph}_{3} \mathrm{PX}\right) \mathrm{AlCl}_{3}\left[\mathrm{~W}\left(\mathrm{XPPh}_{3}\right)(\mathrm{CO})_{5}\right] \\ \mathrm{X}=\mathrm{O} & 290 & 125-180^{\circ} & 159^{\circ} & 180.0^{\circ} & 134.3^{\circ} \\ \mathrm{X}=\mathrm{S} & 16 & 102-117^{\circ} & 108^{\circ} & 109.6^{\circ} & 113.2^{\circ} \\ \mathrm{X}=\mathrm{Se} & 9 & 97-111^{\circ} & 102^{\circ} & 107.2^{\circ} & 109.2^{\circ}\end{array}$

(a) From data retrieved from the Cambridge Crystallographic Database [3] 
Table 6a:

Mulliken and Lowdin $\mathrm{X}-\mathrm{P}$ bond orders for the compounds $\mathrm{XPPh}_{3}(\mathrm{X}=\mathrm{O}, \mathrm{S}, \mathrm{Se})$

Model/basis set

$\mathrm{OPPh}_{3}$

$\mathrm{SPPh}_{3}$

$\mathrm{SePPh}_{3}$

Mulliken Lowdin Mulliken Lowdin Mulliken Lowdin

$\begin{array}{lllllll}\text { HF/STO-3G } & 1.334 & 1.332 & 1.017 & 1.062 & 0.950 & 1.002\end{array}$

$\begin{array}{lllllll}\mathrm{HF} / 3-21 \mathrm{G}^{*} & 1.899 & 1.955 & 1.569 & 1.586 & 1.442 & 1.450\end{array}$

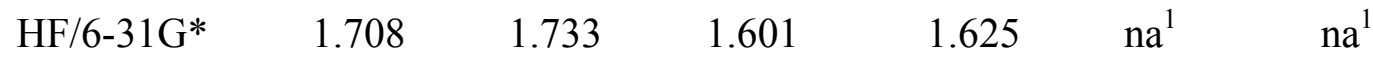

${ }^{1} 6-31 \mathrm{G}^{*}$ basis set not available for Se

Table 6b:

Mulliken and Lowdin atomic valencies $(\mathrm{X}$ and $\mathrm{P})$ for the compounds $\mathrm{XPPh}_{3}(\mathrm{X}=\mathrm{O}$, $\mathrm{S}, \mathrm{Se})$

Atom Valency

\begin{tabular}{lllllllllllll} 
& \multicolumn{3}{c}{ HF/STO-3G } & \multicolumn{3}{c}{ HF/3-21G* } & \multicolumn{3}{c}{ HF/6-31G* } \\
& $\mathrm{X}=\mathrm{O}$ & $\mathrm{X}=\mathrm{S}$ & $\mathrm{X}=\mathrm{Se}$ & $\mathrm{X}=\mathrm{O}$ & $\mathrm{X}=\mathrm{S}$ & $\mathrm{X}=\mathrm{Se}$ & $\mathrm{X}=\mathrm{O}$ & $\mathrm{X}=\mathrm{S}$ & $\mathrm{X}=\mathrm{Se}$ \\
$\mathrm{P}($ Mulliken) & 3.859 & 3.711 & 3.710 & 4.213 & 3.995 & 3.889 & 4.543 & 4.418 & - \\
$\mathrm{P}($ Lowdin) & 3.925 & 3.822 & 3.828 & 4.938 & 4.856 & 4.740 & 5.063 & 4.938 & - \\
$\mathrm{X}($ Mulliken) & 1.667 & 1.270 & 1.164 & 2.015 & 1.668 & 1.593 & 1.777 & 1.648 & - \\
$\mathrm{X}$ (Lowdin) & 1.646 & 1.300 & 1.002 & 1.956 & 1.867 & 1.752 & 1.993 & 1.944 & -
\end{tabular}


Table 7: Diagonal terms $\mathrm{H}_{\mathrm{ii}}(\mathrm{eV})$ for $\mathrm{O}, \mathrm{S}$, and Se ns- and np-orbitals

\begin{tabular}{|l|l|l|l|}
\hline Orbital & Oxygen $(n=2)$ & Sulfur $(n=3)$ & Selenium $(n=4)$ \\
\hline ns & -32.3 & -20.7 & -20.8 \\
\hline$n p$ & -15.8 & -11.6 & -10.8 \\
\hline
\end{tabular}


Table 8: Angle of lowest energy for a three-body, seven-orbital $\sigma$ - and $\pi$-model as a function of the energy of the tungsten $\sigma$ - and $\pi$-orbitals.

\begin{tabular}{|l|l|l|l|}
\hline $\mathrm{E}(\mathrm{M} \sigma, \mathrm{M} \pi)$ & $\mathrm{X}=\mathrm{O}$ & $\mathrm{X}=\mathrm{S}$ & $\mathrm{X}=\mathrm{Se}$ \\
\hline$(-2,-5)$ & $180^{\circ}$ & $180^{\circ}$ & $180^{\circ}$ \\
\hline$(-3,-6)$ & $133^{\circ}$ & $117^{\circ}$ & $113^{\circ}$ \\
\hline$(-4,-7)$ & $103^{\circ}$ & $97^{\circ}$ & $95^{\circ}$ \\
\hline$(-5,-8)$ & $94^{\circ}$ & $90^{\circ}$ & $90^{\circ}$ \\
\hline
\end{tabular}




\section{Captions to Figures}

Figure 1. The structures of $\left[\mathrm{W}\left(\mathrm{XPPh}_{3}\right)(\mathrm{CO})_{5}\right]$, (a) $\mathrm{X}=\mathrm{O}$; (b) $\mathrm{X}=\mathrm{S}$; (c) $\mathrm{X}=\mathrm{Se}$.

Figure 2. Views of the molecule along the W-C(1) vector, showing the different orientation of the $\mathrm{P}-\mathrm{X}$ vector with respect to the equatorial carbonyl groups. The phenyl rings, and the oxygen atoms of the $\mathrm{CO}$ groups have been excised. The $\mathrm{C}(3)-$ $\mathrm{W}(1)-\mathrm{X}(1)-\mathrm{P}(1)$ torsion angles are $32.8^{\circ}, 10.3^{\circ}$, and $28.0^{\circ}$ respectively for the $\mathrm{O}, \mathrm{S}$ and Se compounds.

Figure 3. Three-body model system used in EHMO calculations

Figure 4. Orbital interaction diagram for a three-body, five-orbital model system with $\sigma$-bonding only, when M-X-P is $180^{\circ}$

Figure 5. Plot of the energy difference between $180^{\circ}$ and $90^{\circ}$ for the three-body, fiveorbital model with $\sigma$-bonding only. 
(a)

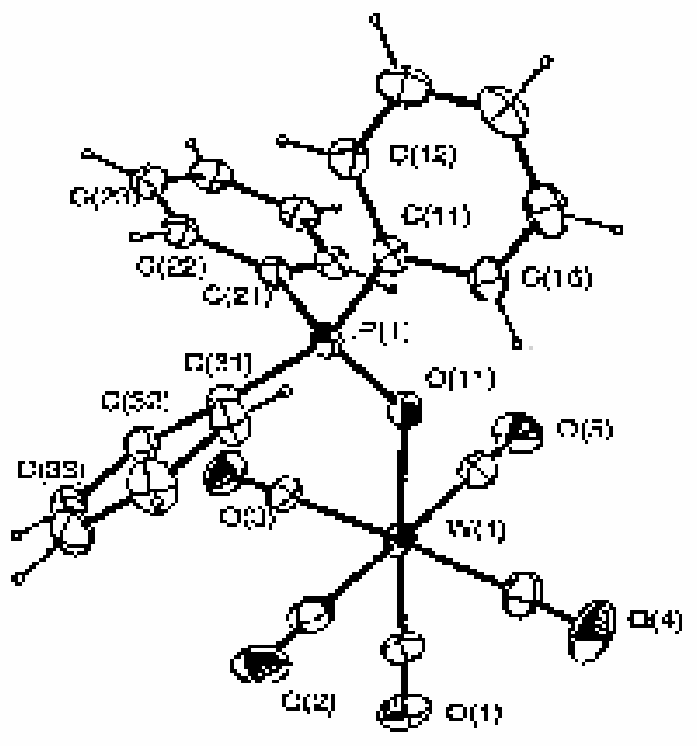

(b)

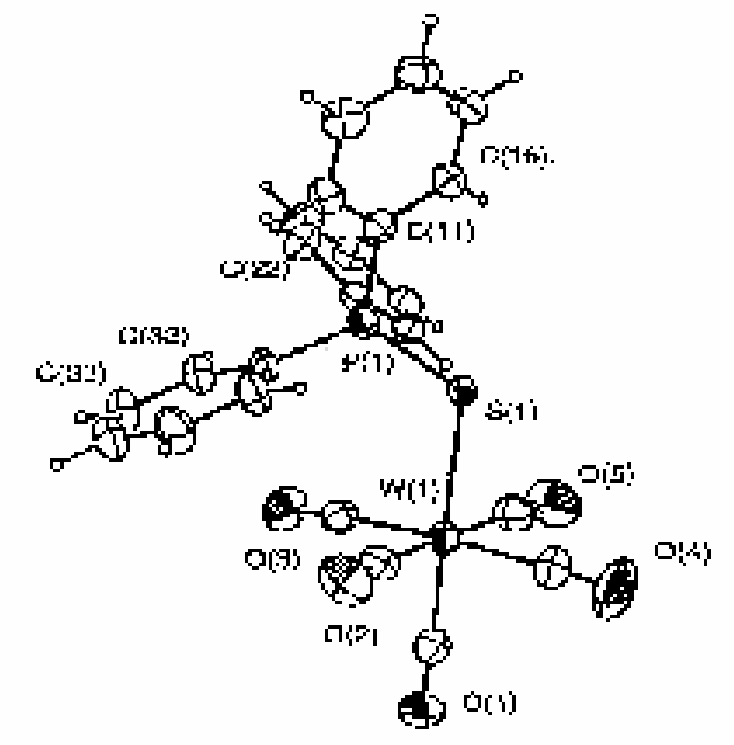

(:)!

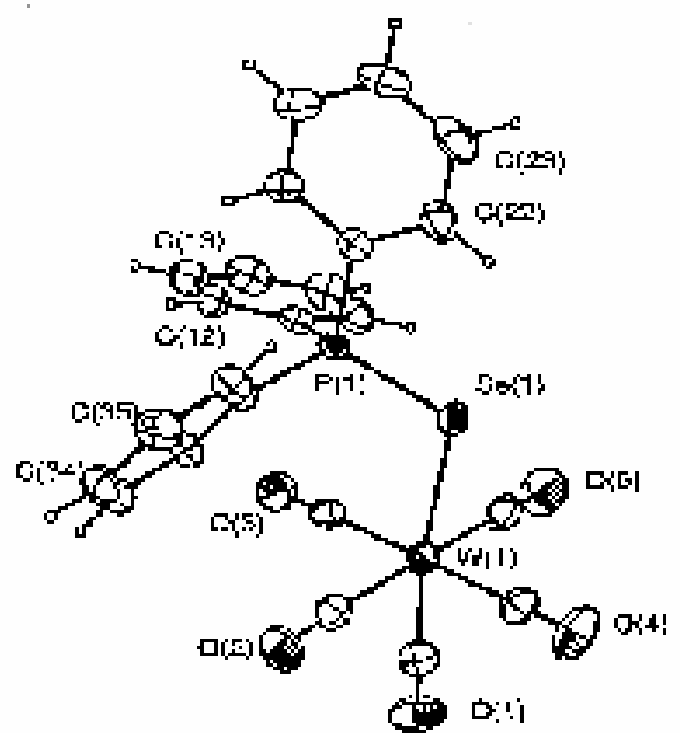



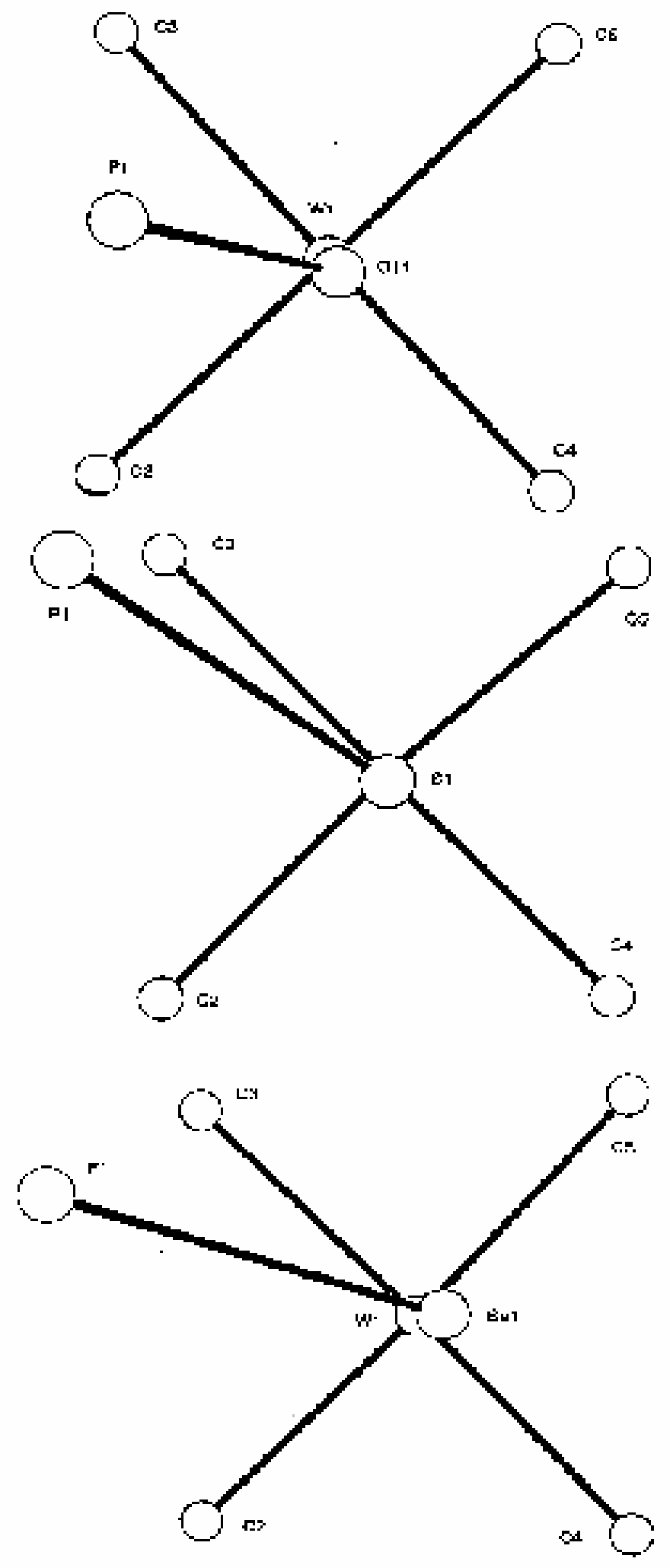


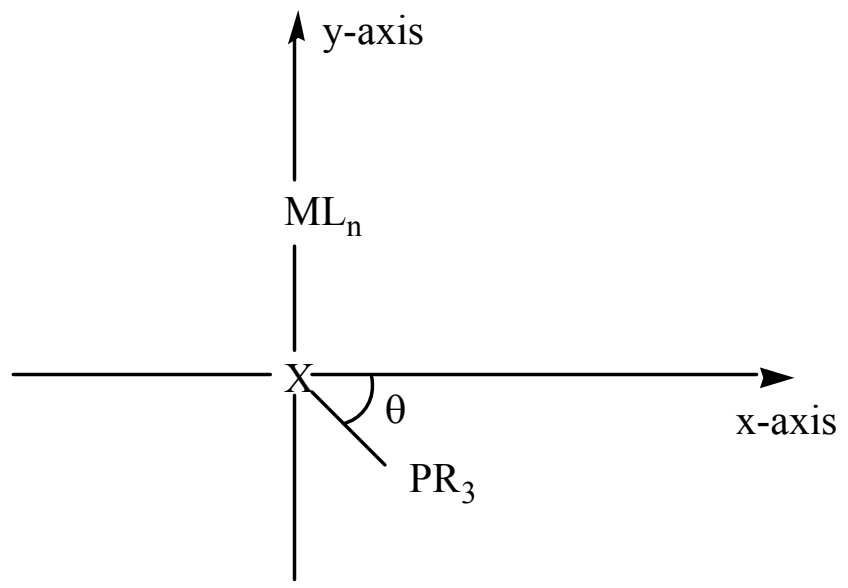

Figure 3: Three-body model system used in EHMO calculations 


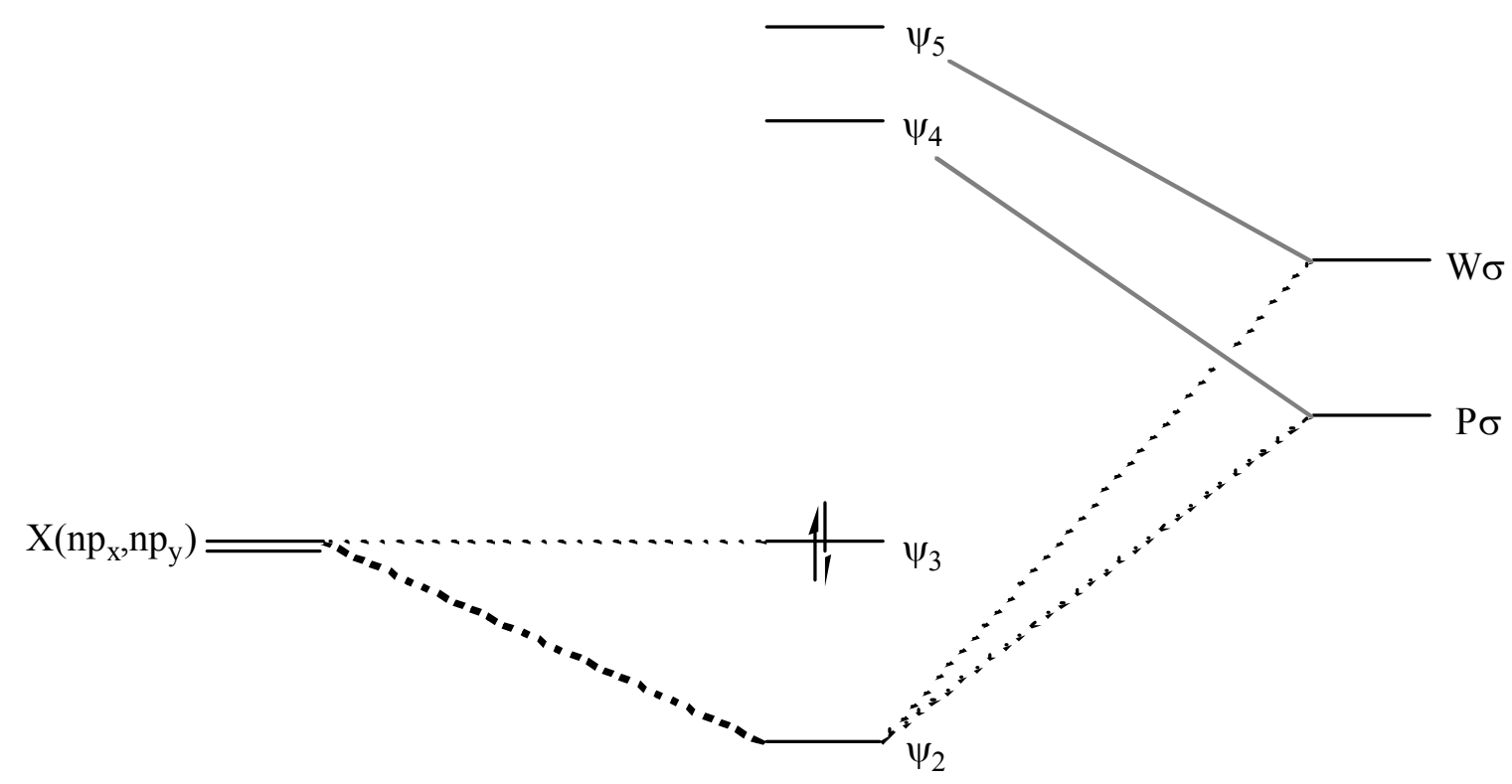

$\mathrm{X}(\mathrm{ns})$

$\psi_{1}$

Figure 4: Orbital interaction diagram for a three-body, five-orbital model system with $\sigma$-bonding only, when M-X-P is $180^{\circ}$ 


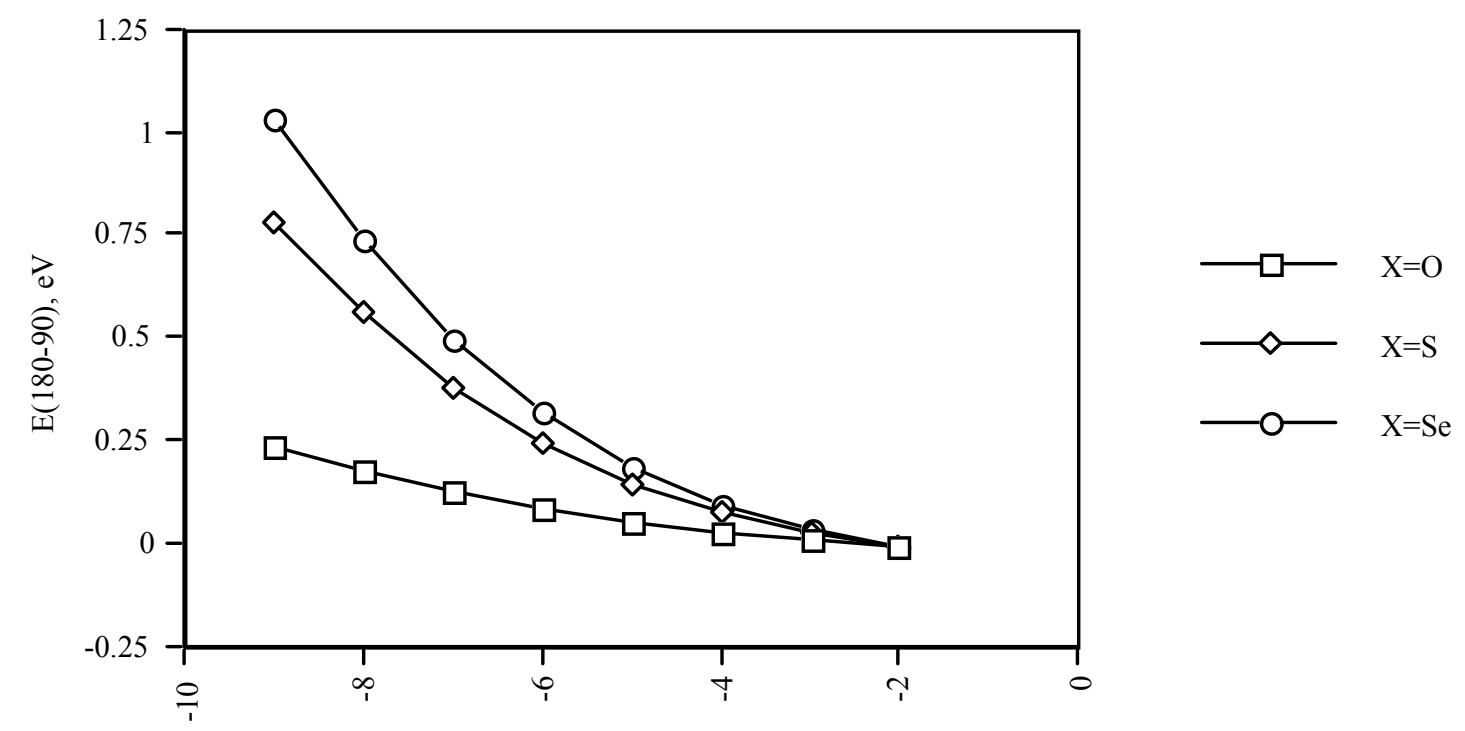

Energy of metal sigma orbital $(\mathrm{eV})$

Figure 5: Plot of the energy difference between $180^{\circ}$ and $90^{\circ}$ for the three-body, fiveorbital model with $\sigma$-bonding only. 